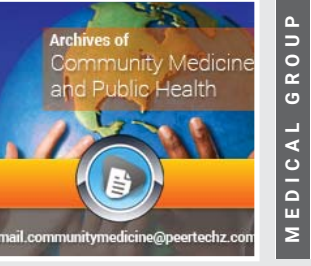

\section{Myths and Misconceptions about Communication Disorders: A Survey in North Karnataka region}

\author{
K Sandhya ${ }^{1 *}$, S Akshata ${ }^{2}$, K N Meghana ${ }^{3}$ and N Sushmitha ${ }^{4}$ \\ ${ }^{1}$ Assistant Professor in Speech Language Pathology, SDM Institute of Medical Sciences and Hospital, \\ SDM University, Dharwad, Karnataka, India \\ ${ }^{2}$ Speech Language Pathologist, Pristine Rehab Care, California, USA \\ ${ }^{3}$ Speech Language Pathologist, International Foundation of Speech and Happiness, Delhi, India \\ ${ }^{4}$ Audiologist and Speech Language Pathologist, S Nijalingappa medical college and HSK hospital and \\ research centre, Bagalkot, Karnataka, India
}

Received: 06 September, 2021

Accepted: 25 October, 2021

Published: 26 October, 2021

*Corresponding author: K Sandhya, Assistant Professor in Speech Language Pathology, SDM Institute of Medical Sciences and Hospital, SDM University, Dharwad, Karnataka, India, Tel: 9035362883 E-mail: gangollibhoomi@gmail.com

Keywords: Myths; Misbelieves; Communication disorders; North Karnataka; Survey

Copyright: @ 2021 Sandhya K, et al. This is an openaccess article distributed under the terms of the Creative Commons Attribution License, which permits unrestricted use, distribution, and reproduction in any medium, provided the original author and source are credited.

https://www.peertechzpublications.com

\section{Check for updates}

\title{
Abstract
}

Introduction: Communication disorders are highly prevalent in India especially in children. Early identification and treatment can prevent children from falling behind academically, socially, and in other key areas. However, identifying children with communication disorders and providing rehabilitation at an early stage is challenging in Indian scenario. Though $21^{\text {st }}$ century has progressed drastically towards the rehabilitation of various communication disorders effectively, not all the regions in India are accepting the scientific rehabilitation. Due of lack of awareness, ignorance and stigma related to communication disorders, some open prejudices still persist in our country, making it difficult for people with communication disorders to have their condition recognized and to seek rehabilitation. However beforehand it is important to know the origin and degree of the problem so that appropriate remedy can be sought. Hence the present study makes one such effort, to study the extent of myths widely spread over north Karnataka region.

Method: A questionnaire consisting of 10 questions which focus on myths and misbelieves regarding communication disorders was administered on a total of Six hundred participants in the age range of 18 to 80 years.

Results: Results indicated presence of myths in rural population with respect to communication disorders compared to urban population as well as more misconceptions were noticed in older population when compared to younger ones.

Conclusion: From the results it can be concluded that further necessary programs needs to be implemented in rural areas and for older age groups of North Karnataka region to create awareness in this regard.

\section{Introduction}

Communication is a systematic process by which an individual can exchange information and convey ideas. A communication disorder is any disorder that affects an individual's ability to comprehend, detect, or apply language and speech to engage in discourse effectively with others [1]. Communication disorders are highly prevalent in India especially in children [2]. It is reported that 21 out of every 1000 children have hearing loss [3]. Prevalence of hearing impairment was reported to be $7.3 \%$ in rural population of Lucknow district whereas prevalence of mental retardation was reported to be $2.3 \%$ in Karnataka [4]. Highest prevalence was reported for auditory disorders (62\%) followed by language disorders (24\%) and then speech disorders (14\%) [5.6]. A study [7] was conducted on 15441 individuals and reported prevalence of communication disorder to be $6.07 \%$ in a rural population of Karnataka. Screening of 2010 school children in the age range of 6-12 years for communication disorders was carried out in rural and urban Mysuru regions. Results indicated that the disorders that were more prevailed in school children include intellectual disability $(10 \%)$, specific language impairment $(7.8 \%)$, multiple disorders (2.2\%), and Autism Spectrum Disorders (0.9\%). Among the speech disorders, Articulation/ Phonological disorder were found to be more common (18.6\%) compared to other speech disorders including 
Fluency disorders $(10.8 \%)$, Voice disorders $(2.6 \%)$, Childhood dysarthria (1.7\%) and Hypernasality with repaired cleft-lip \&Palate $(1.3 \%)$ [8].

Occurrence of speech, language and hearing problems in the early childhood can cause severe impairment in literacy, cognition and overall development of the child. Early identification of these communication disorders is essential for timely remedial intervention leading to improved longterm outcomes. Early identification and treatment can prevent children from falling behind academically, socially, and in other key areas at the critical time. However, identifying children with communication disorders and providing rehabilitation at an early stage is challenging in Indian scenario. Though $21^{\text {st }}$ century has shown considerable progress towards the rehabilitation of various communication disorders effectively, not all the regions in India are accepting the scientific rehabilitation for speech and language disorders. Awareness about communication disorders in general population is an area of concern. Due to lack of awareness, ignorance and stigma related to communication disorders, there are various myths and misconceptions which are prevailing in our country.

Myths \& misconceptions can be referred to as any ill beliefs, mistaken thoughts, ideas or notions or incorrect information regarding communication disorders and its treatment. A myth has different meanings for the believer, the anthropologist, the folklorist, the psychologist, and the literary critic [9]. The public view towards communication disorders is negative, stigmatized, uninformed and fearful entity right from the ancient time to till date which varies according to age, race, ethnicity, religion, culture, tradition and education of the different community [10]. Unfortunately, some commonly held beliefs about communication disorders which are scientifically proven untrue still persist.

Very little studies have been documented in literature regarding myths and misbeliefs with respect to communication disorders. While most of the studies have been reported in western literature, yet there is dearth of data pertaining to Indian studies. European folklore regarded physically deformed or mentally retarded children as the offspring of fairies, elves or other sub-human beings [11]. Cleft lip and/or palate are one of the most common birth defects and one that requires interdisciplinary management. The earliest traceable history of cleft lip and palate considered congenital anomalies to be evidence of the presence of an evil spirit in the affected child, curse from God, evil attack, effect of black magic, presence of fibroid in the womb, or reincarnation of an accident victim. In developing countries, superstitious beliefs such as witchcraft, gods and retribution are still attributed as possible causes of cleft lip and palate [12]. While in developed countries, maternal impression, stellar influences, mechanical causes and folklore are attributed as possible causes of cleft lip and palate [13] Among rural communities in the Indian subcontinent, the family where deformed child is born is held in low esteem until certain purifying rituals have been performed [14]. A study in rural part of India revealed that almost all parents blamed the occurrence of cleft lip and palate on a curse, an act of evil or retribution for past sins [15]. A pilot study to understand cultural perspectives on cleft anomalies in the community of Hyderabad, India, and its rural outskirts revealed that of the 23 families interviewed, 12 mothers believed the cleft was caused by an eclipse [16].

African American folk myths about stuttering states that people believed that stuttering is caused because of improper foods when breast feeding the infant, the mother seeing a snake during pregnancy, the work of the devil and so on. A Study [1719] on stuttering- related myths reported that people believed that a person stuttered because of failure to inform ancestors of imminent childbirth, supernatural powers, bad karmas and having short tongue. A presentation at International Stuttering Awareness Day Online Conferences stated that in Africa it was believed stammering in young children was due to eating grasshoppers [20]. There existed a myth which stated that abnormal children are born because of curse inflicted on them and till today hostility towards the facially deformed individuals still exits [21]. Similarly myths and misconceptions about hearing impairment and other communication disorders also prevail in most of the regions. However no documentations are available in this regard.

The damaging consequences of such notions results in social rejection, isolation and restriction of opportunities. This lack of understanding can make it difficult for people with communication disorders to have their condition recognized and to seek, accept or reveal rehabilitation. Prior to creating awareness and providing rehabilitation, it is important to know the origin and degree of the problem so that appropriate remedy can be sought. Though studies on myths and misconceptions are conducted in few parts of India, no literature is available in connection with Karnataka or its regions. The present study makes one such effort, where the survey focuses on extent of myths widely spread over north Karnataka region.

More the myths and misbeliefs lessen the chances of people being aware of the problem and in turn probability of identification of the disorders becomes lesser which leads to non-treatment and/or late treatment of a particular speech and hearing disability. Hence, it is essential to identify such fields, make the people aware, so that appropriate and early intervention can be initiated. The current study aims to survey myths and misconceptions about communication disorders in region of northern Karnataka so as to plan and implement proper measures towards creating awareness concerning communication disorders

\section{Methods}

The study was carried out in five phases over a period of approximately 6 months.

i. Development of the questionnaire

ii. Questionnaire validation

iii. Selection of the participants

iv. Administration of questionnaire and data collection 


\section{v. Data Analysis}

\section{Development of the questionnaire}

The questionnaire was developed using descriptive survey design. As there was no questionnaire which provides information on myths of communication disorders, a researcher made questionnaire was planned to develop. An initial draft consisted of 30 closed ended 'yes-no- not sure' type questions. To make it a research made questionnaire, it was prepared with the help of experienced Speech-Language Pathologists and Audiologists, which discusses basic information on awareness of a person towards communication disorders. Questions were formed based on professional's knowledge on myths and misbeliefs which they have come across in their service. Patients who visited the clinic were asked for the causes of speech and hearing disorders and if there were any misbelieves found in their answers, those questions were also included in the questionnaire. Questionnaire was designed in English and translated in Kannada for the ease of administration. These questions were given to general public to rate according to their relevance. Most relevant 10 questions were considered for the final study (Annexure 1).

\section{Questionnaire validation}

Prior to the data collection the initial draft was subjected to pilot study, to check the validity and the reliability of the questions. In this process, two types of validity were tested; responses to each item were scrutinized to identify any misunderstandings and ambiguity. Items found to be unclear or ambiguous were modified thereby improving face validity. Expert opinions, review of literature and pre-testing of openended questions were used to improve the content validity.

\section{Selection of the participants}

Simple random sampling method was used for selecting participants of the study as it is considered as a suitable method to gather quantitative data from questionnaires. Random sampling lets the results to be accurately reflecting the entire population. Using this technique, each individual in the selected population is randomly selected and has as much chance of being selected as anyone else. Based on random sampling a total of Six hundred participants in the age range of 18 to 80 years were included in the study. Further they were grouped into three groups based on their age i.e. group I-young adults (ages 18-35 years), group II- middle-aged adults (ages 36-55 years) and group III- older adults (aged older than 55 years). All the participants were native Kannada speakers from urban and rural areas in the northern part of Karnataka. Individuals having hearing impairment, Intellectual disability or any other conditions which cause poor understandings of questions were excluded from the study.

\section{Administration and scoring}

Test environment: The study was carried out at various public places like, clinics, hospitals, public gatherings and individuals who attended the speech and hearing camps organized in Dharwad, Hubli, Belgaum and Bijapur. Prior face validity and content validity. Followed by pilot study,

to conducting the survey, nature and purpose of study was explained to all participants in Kannada and consent was taken from each individual.

Procedure: The questionnaire was administered by the investigator by briefing the participants regarding the study. Medium of communication between Investigator and the participant was in Kannada. The investigator asked the questions to the participant one at a time. The participants were instructed to either say 'Yes', 'No' or 'Not sure' to the questions. The participants were expected to answer each question in 5 seconds. The time taken for data collection is 10 minutes for each participant.

\section{Data analysis}

Thus questionnaire administration was done to all the six hundred subjects in the same manner. The scores for each participant were awarded based on the response. If the response was a myth, it was scored as 0 and if it was not a myth, it was assigned the value of 1 . Data was grouped in terms of age range, gender and geographical location viz. rural and urban for further analysis. Scores were tabulated separately for each group and further statistical analysis was done using SPSS software (Version 20).

\section{Results}

Frequency distribution was carried out to understand the occurrence of myths for each response across 10 questions. Overall results showed high mean for Q1 (73\%), Q3 (68\%), Q6 (55.6\%) and Q9 (71.7\%) indicating presence of myth for those questions. Descriptive statistics was done to find out mean and standard deviation (SD) for all the 10 questions in both rural vs urban population, males vs. females and across age groups. Further One way ANOVA was performed to study the significant differences in performance within and across the groups and geographical area.

The mean and SD of responses across the three age groups is given in Table 1. When compared across age groups middle and older adults showed more myths compared to younger group. Mean was found to be significantly different for Q1

Table 1: Mean and SD of myths and misconceptions across age groups.

\begin{tabular}{|c|c|c|c|c|c|c|}
\hline Questions & \multicolumn{2}{|c|}{$\begin{array}{c}\text { Gropu 1 (Young } \\
\text { Adults) }\end{array}$} & \multicolumn{2}{c|}{$\begin{array}{c}\text { Group 2 (Middle aged } \\
\text { adults) }\end{array}$} & \multicolumn{2}{c|}{$\begin{array}{c}\text { Group 3 (Older } \\
\text { Adults) }\end{array}$} \\
\hline & Mean & SD & Mean & SD & Mean & SD \\
\hline $\mathrm{Q}_{1}$ & 1.23 & 0.41 & 1.31 & 0.47 & 1.49 & 0.59 \\
\hline $\mathrm{Q}_{2}$ & 1.39 & 0.5 & 1.48 & 0.55 & 1.51 & 0.56 \\
\hline $\mathrm{Q}_{3}$ & 1.72 & 0.47 & 1.78 & 0.47 & 1.67 & 0.56 \\
\hline $\mathrm{Q}_{4}$ & 1.6 & 0.77 & 1.69 & 0.76 & 1.71 & 0.75 \\
\hline $\mathrm{Q}_{5}$ & 1.43 & 0.61 & 1.5 & 0.63 & 1.46 & 0.56 \\
\hline $\mathrm{Q}_{6}$ & 1.6 & 0.54 & 1.63 & 0.57 & 1.75 & 0.53 \\
\hline $\mathrm{Q}_{7}$ & 1.25 & 0.58 & 1.35 & 0.63 & 1.38 & 0.65 \\
\hline $\mathrm{Q}_{8}$ & 1.49 & 0.63 & 1.54 & 0.63 & 1.59 & 0.68 \\
\hline $\mathrm{Q}_{9}$ & 1.8 & 0.48 & 1.8 & 0.5 & 1.89 & 0.57 \\
\hline $\mathrm{Q}_{10}$ & 1.29 & 0.59 & 1.5 & 0.68 & 1.56 & 0.71 \\
\hline
\end{tabular}

Citation: Sandhya K, Akshata S, Meghana KN, Sushmitha N (2021) Myths and Misconceptions about Communication Disorders: A Survey in North Karnataka region. Arch Community Med Public Health 7(3): 212-217. DOI: https://dx.doi.org/10.17352/2455-5479.000164 
$(\mathrm{F}(2,598)=9.126, \mathrm{p}=0.00), \mathrm{Q} 7(\mathrm{~F}(2,598)=2.407, \mathrm{p}=0.021)$ and $\mathrm{Q} 10(\mathrm{~F}(2,598)=8.466, \mathrm{p}=0.00)$ between younger and middle age adults and younger and older adults. However there was no significant difference between middle age and older adults (Table 1).

With respect to geographical area, mean was found to be higher for $\mathrm{Q}_{1}(\mathrm{~F}(1,599)=3.060, \mathrm{p}=0.043), \mathrm{Q}_{2}(\mathrm{~F}(1,599)=4.986$, $\mathrm{p}=0.026)$ and $\mathrm{Q} 10(\mathrm{~F}(1,599)=3.012, \mathrm{p}=0.047)$ in rural population and significant difference was found for these questions among rural and urban population. The mean and SD of responses for questions for rural and urban population is given in Graph 1. However, no significant difference was seen in gender across questions. The mean and SD depicting results across genders are shown in Graph 2 (Tables 2,3 Graphs 1,2).

\section{Discussion}

Despite the increase in knowledge and widespread access to medical care, beliefs contrary to science still occur in most developing countries. The present study aimed to survey myths and misconceptions about communication disorders in region of northern Karnataka. The study results indicate the presence of myths concerning importance of hearing for speech and language development and curse for pregnant mother and child

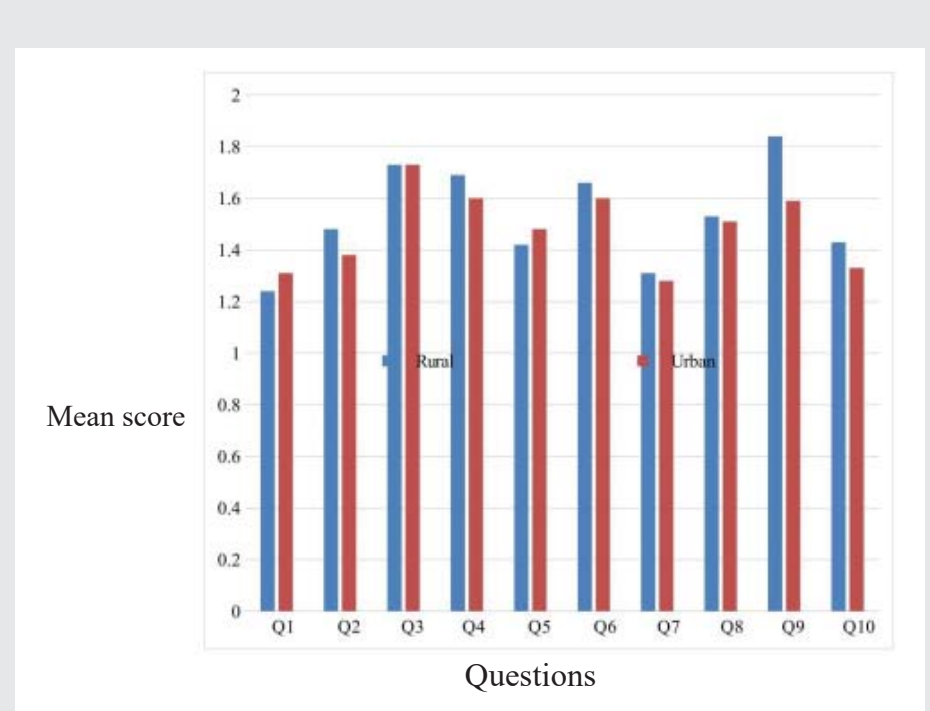

Graph 1: Mean scores of myths and misconceptions across geographical area.

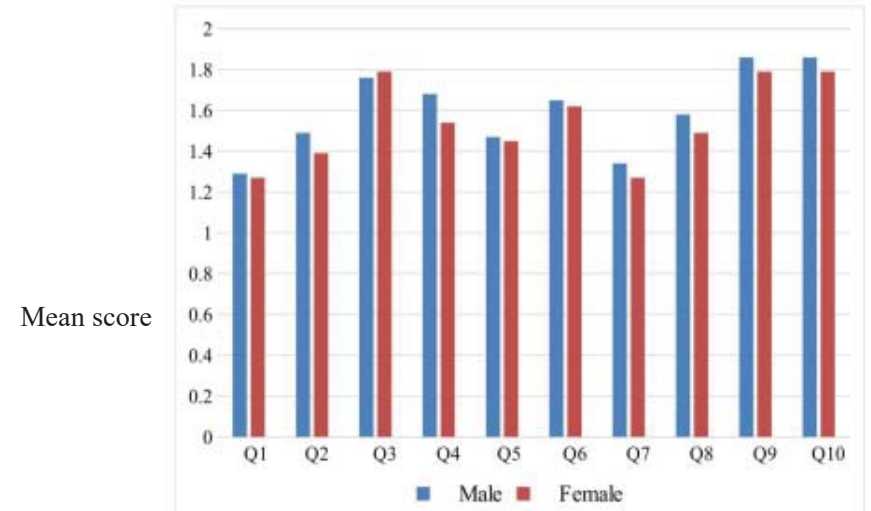

Questions
Table 2: Mean scores of myths and misconceptions across geographical area.

\begin{tabular}{|c|c|c|c|c|}
\hline & \multicolumn{2}{|c|}{ Rural } & \multicolumn{2}{c|}{ Urban } \\
\hline & Mean & SD & Mean & SD \\
\hline$Q_{1}$ & 1.23 & 0.46 & 1.31 & 0.41 \\
\hline$Q_{2}$ & 1.48 & 0.53 & 1.38 & 0.51 \\
\hline$Q_{3}$ & 1.73 & 0.47 & 1.73 & 0.50 \\
\hline$Q_{4}$ & 1.69 & 0.77 & 1.60 & 0.76 \\
\hline$Q_{5}$ & 1.42 & 0.59 & 1.48 & 0.63 \\
\hline$Q_{6}$ & 1.66 & 0.58 & 1.60 & 0.54 \\
\hline$Q_{7}$ & 1.31 & 0.60 & 1.28 & 0.61 \\
\hline$Q_{8}$ & 1.53 & 0.63 & 1.51 & 0.64 \\
\hline$Q_{9}$ & 1.84 & 0.47 & 1.59 & 0.51 \\
\hline$Q_{10}$ & 1.43 & 0.66 & 1.33 & 0.62 \\
\hline
\end{tabular}

Table 3: Mean scores of myths and misconceptions across gender.

\begin{tabular}{|c|c|c|c|c|}
\hline & \multicolumn{2}{|c|}{ Male } & \multicolumn{2}{|c|}{ Female } \\
\hline & Mean & SD & Mean & SD \\
\hline$Q_{1}$ & 1.99 & 0.48 & 1.27 & 0.46 \\
\hline$Q_{2}$ & 1.49 & 0.56 & 1.39 & 0.50 \\
\hline$Q_{3}$ & 1.76 & 0.50 & 1.79 & 0.48 \\
\hline$Q_{4}$ & 1.68 & 0.55 & 1.54 & 0.78 \\
\hline$Q_{5}$ & 1.47 & 0.66 & 1.45 & 0.59 \\
\hline$Q_{6}$ & 1.65 & 0.55 & 1.62 & 0.55 \\
\hline$Q_{7}$ & 1.34 & 0.64 & 1.27 & 0.59 \\
\hline$Q_{8}$ & 1.58 & 0.68 & 1.49 & 0.61 \\
\hline$Q_{9}$ & 1.86 & 0.48 & 1.79 & 0.61 \\
\hline$Q_{10}$ & 1.86 & 0.48 & 1.79 & 0.61 \\
\hline
\end{tabular}

for having communication disorders. The results of the study indicates that older age group has myths and misconceptions regarding importance of hearing for speech and language acquisition and there still exists the belief that black magic and curse leads to mental retardation in children and pregnant mothers previous life sins causes cleft lip and palate. A study reported that individuals considered curse as a factor causing infertility or disordered children. The results also revealed that rural population are less aware regarding the importance of hearing for speech and language development (Q1, Q2), as well as in the belief of past life sin for having a child with cleft lip and palate (Q10) [22]. A study [23] which revealed that there is lack of awareness about hearing loss and is more misconceptions about hearing loss in rural area compared to urban area which is prop up with our study. Patients' reaction to treatment and treatment outcome determines largely or partly by what they believe. As India being a rural based country, lack of awareness and educational status might have contributed to the development of misbelieves regarding communication disorders which needs proper attention [24].

\section{Conclusion}

The speech language pathologist's understanding of a patient's cultural background is extremely relevant for a successful transmission of new ideas, techniques and beliefs to them. Hence knowing their beliefs about whatever condition

Citation: Sandhya K, Akshata S, Meghana KN, Sushmitha N (2021) Myths and Misconceptions about Communication Disorders: A Survey in North Karnataka region. Arch 
they present with is foremost and paramount. Carrying out researches on myths and misconceptions may help professionals to understand a patient's idea of the cause of his or her condition will facilitate the speech language pathologist and patients with communication disorders working closely together which in turn helps in counseling the patient. A limitation of the study is the sample size under each group (age, gender and geographical area) and hence, generalization becomes difficult. Similar studies can be carried out in a large population, among various socio-cultural groups, different districts and states of Karnataka to understand the variations in beliefs. In future, community based awareness programs regarding causes, symptoms, characteristics, preventive measures and treatment options of communication disorders can be planned by the professionals which improves the knowledge of disorders in general public.

\section{Ethical approval}

Appropriate ethical standards are upheld during the data collection and informant consents were taken for the participation of the study.

\section{References}

1. Owens C, Dein S (2006) Conversion disorder: the modern hysteria. Advances in Psychiatric Treatment 12: 152-157. Link: https://bit.ly/30Xrakm

2. Collins JW, O'Brien NP (2011) The greenwood dictionary of education Greenwood 86

3. Indian - survey of disabled persons, July 2002 -Dec 2002, NSS 58th Round.

4. Singh AP, Chandra MR, Diya D, Chandra R, Bhushan V (1980) Prevalence of deafness in a rural population of Lucknow district. Indian Journal Public Health 24: 23-31. Link: https://bit.ly/3b50EYb

5. Kumar M, Antony J, Madu CN, Montgomery DC, Park SH(2008) Common myths of 6 stigma demystified. International Journal of Quality and Reliability Management 25: 878-895. Link:https://bit.ly/3GbAuRE

6. Devadiga D, Aiswarya Liz Varghese, Bhat J (2014) Epidemiology of communication disorders and its role in rehabilitation. International Journal of innovation Research and Development 3. Link: https://bit.ly/3B9y2r9

7. Sreeraj K, Suma C, Jayaram G, Sandeep M, Mahima G, et al. (2013) Prevalence of communication disorders in a rural population of India. J Hear Sci 3: 41-49. Link: https://bit.ly/3Ghl9z8

8. Shanbal JC, Arunraj K, Reddy SM (2015) Distribution of communication disorders in primary school children. JAIISH 34: 128-133. Link: https://bit.ly/3bmVnvf

9. Oginni FO, Asuku ME, Oladele AO, Obuekwe ON, Nnabuko RE (2010) Knowledge and cultural beliefs about the etiology and management of orofacialclefts in Nigeria's major ethnic groups. Cleft Palate Craniofac J 47: 327-334. Link: Link: https://bit.ly/3EcavaT
10. Kulhara P, Avasthi A, Sharma A (2000) Co-Religious Beliefs in Schizophrenia: A Study from North India. Psychopathology 33: 62-68. Link: https://bit.ly/3CiSuOg

11. Haffter C (1968) The changeling: history and psychodynamics of attitudes to handicapped children in European folklore. Journal of the History of Behavioural Science 4: 55-61. Link: https://bit.ly/3b74Syl

12. Converse JM, Hogan VM, McCarthy JG (1977) Cleft lip and palate. In: Converse JM, editor. Reconstructive Plastic Surgery. 2nd ed. Philadelphia: Saunders 1930

13. Adeyemi TA (2014) Myths and cultural beliefs about cleft lip and palate still occurs even in the $20^{\text {th }}$ century. Oral health Dent Manag 13: 2. Link: https://bit.ly/3pzuRHe

14. Shaw WC (1978) Folklore surrounding facial deformity and the origins of facia prejudice. Br J Plast Surg 34: 237-246. Link: https://bit.ly/3Cdo0GW

15. Shazly M, Bakry R, Tohamy A, Ali WM, Elbakry S, et al. (2010) Attitudes towards children with clefts in rural Muslims and Hindu societies. Ann Plast Surg 64 780-783. Link: https://bit.ly/3Cbc08

16. Aparajit N, Sumeet NM, Deepak N, Srinivas GR, Rajgopal RR, et al. (2013) Perception of family members of children with cleft lip and palate in Hyderabad, India, and Its Rural outskirts regarding Craniofacial Anomalies: A Pilot Study. Cleft Palate Craniofac J 50: e41-e46. Link: https://bit.ly/2ZiDU3Y

17. Robinson TL, Crowe TA (1998) Culture-Based Considerations in Programming for Stuttering interventions with African American Clients and Their Families. Lang Speech Hear Serv Sch 29: 172-179. Link: https://bit.ly/3C75GiB

18. Harsha K (1998) Issues of culture and stuttering: A South African perspective, International stuttering awareness day online conference. Link: https://bit.ly/3E9opL5

19. Thomas (2000) Ideas in our country, culture, family about what causes stuttering and what should be done about it. International stuttering awareness day online conference.

20. Berinyuy J (2000) Some past stories on prevention and causes of Stammering in the NSO land in Cameroon. International stuttering awareness day online conference. Link: https://bit.ly/3CdnCrW

21. Lukong J (2000) Stuttering in the Lukong family. Is it natural or curse from the God. International stuttering awareness day online conferences.

22. McDonald E (2004) A Global Perspective on Infertility: An Under Recognized Public Health Issue, Carolina Papers, University Center for International Studies the University of North Carolina at Chapel Hill 5.

23. Manjunatha YN (2014) Awareness and misconception in the area of hearing loss: A survey in rural and tribal population. Post graduate research project. All India Institute of Speech and Hearing, Mysuru.

24. Jabbal A (2011) Government of India. "Indian States Census 2011". Census Organization of India. 2011. Link: https://bit.ly/3jy3Pw9 


\section{Annexure 1}

\begin{tabular}{|c|l}
\hline Q1 No & \\
\hline Q1 & There is no need for auditory skill for Speech and language development \\
\hline vQ3 & Children with hearing impairment cannot learn speech \\
\hline Q4 & Children with hearing impairment should be sent only to Special schools \\
\hline Q5 & Using hearing aids for a few years will help in restoring hearing loss \\
\hline Q6 & Pouring hot oil in the ear will reduce ear pain and ear discharge \\
\hline Q7 & Children who do not talk will start talking as they grow older \\
\hline Q8 & Mental retardation is caused due to black magic, curse and bad deeds of a person \\
\hline Q9 & Home remedies, pills and medications can relieve stuttering \\
\hline Q10 & Having thick tongue leads to stuttering \\
\hline
\end{tabular}

Questionnaire in Kannada Language is available. It will be mailed to the reader on request

Discover a bigger Impact and Visibility of your article publication with Peertechz Publications

\section{Highlights}

* Signatory publisher of ORCID

* Signatory Publisher of DORA (San Francisco Declaration on Research Assessment)

* Articles archived in worlds' renowned service providers such as Portico, CNKI, AGRIS, TDNet, Base (Bielefeld University Library), CrossRef, Scilit, J-Gate etc.

* Journals indexed in ICMJE, SHERPA/ROMEO, Google Scholar etc.

* OAI-PMH (Open Archives Initiative Protocol for Metadata Harvesting)

* Dedicated Editorial Board for every journal

* Accurate and rapid peer-review process

* Increased citations of published articles through promotions

- Reduced timeline for article publication

Submit your articles and experience a new surge in publication services (https://www.peertechz.com/submission).

Peertechz journals wishes everlasting success in your every endeavours.

Citation: Sandhya K, Akshata S, Meghana KN, Sushmitha N (2021) Myths and Misconceptions about Communication Disorders: A Survey in North Karnataka region. Arch Community Med Public Health 7(3): 212-217. DOI: https://dx.doi.org/10.17352/2455-5479.000164 